\title{
A Place-Based Approach to Sustainable Communities: A Case Study from Rapa Nui (Easter Island, Chile)
}

\author{
Pamela A. Mischen ${ }^{1} \&$ Carl P. Lipo ${ }^{2}$ \\ ${ }^{1}$ Department of Public Administration, Binghamton University, Binghamton, NY, USA \\ ${ }^{2}$ Department of Anthropology, Binghamton University, Binghamton, NY, USA \\ Correspondence: Pamela A. Mischen, School of Management, Department of Public Administration, Binghamton \\ University, PO Box 6000, Binghamton, NY 13902-6000, USA. Tel: 1-607-372-3027. E-mail: \\ pmischen@binghamton.edu
}

Received: March 23, 2021

Accepted: July 1, $2021 \quad$ Online Published: July 30, 2021

doi:10.5539/jsd.v14n5p1

URL: https://doi.org/10.5539/jsd.v14n5p1

\begin{abstract}
The failure to account for temporal and spatial contingencies leads to attempts to apply universals to the needs and constraints of communities that may or may not be appropriate. Here, we argue that taking a place-based approach offers a way of incorporating local context to solve issues of sustainability at the scale of communities. We demonstrate this approach with Rapa Nui (Easter Island, Chile), a famous Polynesian island often associated with arguments for non-sustainability. Through detailed analyses of the island's historical context and interviews with present-day governance leaders, we draw three conclusions. First, culture, governance, economy, environment, and equity, often described as "pillars" of sustainability, are inseparable and therefore better described as dimensions of sustainability. These factors are part of the place in which sustainable communities exist and must be integrated into analyses. Second, our findings demonstrate that we must adopt standards for sustainable communities that can change through time. What would have been considered sustainable in prehistoric times is no longer considered sustainable today. Third, globalization can be viewed as a driving force behind these changing views of sustainability. Furthermore, globalization has had both positive (e.g. access to health, education, and economic resources) and negative (e.g. threat to a culture of sustainability) impacts on Rapa Nui.
\end{abstract}

Keywords: sustainable communities, place-based sustainability, temporal aspects of sustainability, globalization, Easter Island

\section{Introduction}

\subsection{Problem Statement}

The assessment of sustainable communities involves the consideration of spatially- and temporally-determined contexts. The spatial dimensions of the community and the resources upon which it depends change over time. For example, contemporary communities are tied to globe-spanning networks, while historic communities often relied upon and, as a consequence, impacted local and circumscribed resources. Consequently, the spatial scales required to assess sustainability for a community can widely vary. Similarly, there are no absolute standards to evaluate community well-being since technology and accepted social practices change over time. For instance, the standards of education and health care have radically changed through time and those changes have to be considered as we compare cases of sustainability. In each instance we explore the sustainability of communities, we must consider appropriate contexts.

Here, we explore how the concept of sustainability has shifted over time to move from entirely global contexts to more spatially specific ones. This spatial shift has resulted in focusing on the evaluation of sustainable communities rather than measuring sustainability more generally. We also examine recent trends to evaluate sustainability in a historic context. We argue that from among the key elements of sustainability that include equity, environment, and economics only issues of equity can be compared through time; other aspects of practices must be discussed in the context of the time and space in which communities exist. This line of thought leads us to argue for a placebased approach to sustainable communities that combine the unique combination of historical-environmental contingencies and populations that live in a particular time and space configuration.

Failure to adopt a place-based approach to sustainability can lead to misunderstandings and erroneous conclusions. 
The pre-European history of Rapa Nui (Easter Island, Chile), for example, is often promulgated as a case of "nonsustainability" in which indigenous populations exploited the island's natural resources leading to a self-imposed societal "collapse" (Diamond, 1995, 2005).

Using recent research, we demonstrate that despite radical changes to the island's environment, past populations thrived in sustainable communities that are consistent within the context of the island and the archaeological past. We then compare the pre-contact case of sustainability with changes that unfolded after contact. Using interviews with key informants we explore the contexts that shape the island's present-day challenges. Together, our findings reveal the importance of considering the environment, economy, equity, culture, and governance as place-based dimensions of sustainability; the significance of adopting standards for sustainability that can change over time; and the essential nature of treating globalization not simply as a threat to sustainability, but as enlarging the spatial scales of systems that affect the sustainability of communities.

\subsection{Literature Review}

Edwards (2005) traces the modern-day "sustainability revolution" to the 1972 United Nations Conference on the Human Environment in Stockholm, Sweden. He notes that popular books such as Robert Allen's How to Save the World (Allen, 1980) and Lester Brown's Building a Sustainable Society (Brown, 1981) helped the cause of sustainability gain wider recognition. In 1984, these early publications were followed by the Worldwatch Institute's publication of its first "State of the World" statement, a document that presented a global perspective on the relations among the Earth's resources and economic development (Brown, 1984). This publication was followed by the Brundtland Commission Report, Our Common Future (World Commission on Environment and Development, 1987). The Brundtland report is widely accepted as the first publication to define sustainable development as "development that meets the needs of the present without compromising the ability of future generations to meet their own needs."

All of these publications share a focus on the Earth as the unit of analysis for assessing sustainability. The publications also share the theme of development. This theme places humans at the center of sustainability as a means of asking questions about whether contemporary standards of living can be indefinitely maintained. The emphasis on development, however, has shifted over time as researchers began to explore "sustainable development" as a plan of action. Starting with the establishment of Agenda 21 (1992), the Millennium Development Goals (2000), and the UN's Sustainable Development Goals (2015), there has been growing recognition that the policies and actions needed for sustainable development cannot be targeted at global change, but rather must be implemented on the scale of individual nations, states/provinces, and communities. In this way, there has been increasing interest in specifying the relevant spatial scale for implementing and assessing sustainability.

This interest in identifying an appropriate spatial scale has led to an interest in exploring sustainability in the context of sustainable communities. A focus on communities provides a scale-specific measurement unit for assessing sustainability. Mischen and colleagues (Mischen et al., 2019) define sustainable communities as:

“...the aggregate of functionally and socially connected individuals and organizations that share collective resources in such a way that engages members in self-determination governance processes resulting in equitable provisioning of the health, educational, and material well-being among its residents while not negatively affecting future generations or other communities' use of these resources."

This definition draws on sustainable development outlined by the Bruntland Commission by focusing on future generations and the environmental, economic, and equity pillars. In this definition, the spatial component is defined in terms of the systems that comprise a community - the set of functional and social connections necessary for the continued well-being of the community's constituents. This definition also emphasizes the potential impact of a particular community on the rest of the communities in the world: a community cannot be sustainable if it negatively impacts other communities. In addition, the definition implies that any single community can be negatively impacted by communities elsewhere. Therefore, in a globally-connected community, any single community's efforts to be sustainable may have consequences for others. Such impact is known as "leakage" (Lima et al., 2019).

Accounting for "leakage" in a plant for community sustainability is problematic. We currently live in a global economy in which communities depend on a complex web of resources and interactions. These interactions have had positive and negative impacts. For instance, the trade of goods between countries has been shown to have disparate effects depending on the level of development: developed nations experience environmental improvements while developing nations experience environmental deterioration as a result of trade liberalization (Baek et al., 2009). On the other hand, using data at the firm level in Japan, Cole and colleagues (Cole et al., 2006) 
showed that Foreign Direct Investment (FDI) had a positive effect on environmental management structure resulting in the adoption of ISO 14001, the production of environmentally friendly products, and environmental cooperation with external agencies.

Likewise, in terms of ecological systems, studies have shown positive and negative effects of trade in goods. Exports from countries with fisheries have been linked to overexploitation (Elsler et al., 2019). The impact on land use and land cover resulting from specialization in agricultural production as a result of trade has been mixed and depends on the country studied (Grau \& Aide, 2008). Rueda and Lambin (Rueda \& Lambin, 2013) found that international demand for environmental preservation via certification by the Rainforest Alliance increased farmer and ecological well-being.

International trade has also resulted in sustainability trade-offs. Marcotullio (Marcotullio, 2001) considered the environmental, human health, and economic impacts of trade and found that while economic and human health outcomes have improved dramatically, many cities are suffering severe environmental quality problems. Singapore, however, provides an important counter-example to this trend. It has overcome many of the negative environmental outcomes resulting from globalization as a result of politics and political culture.

Migration also has sustainability impacts since people, as well as goods, move around the world and this movement has costs and benefits for communities. Discussions about migration in the context of sustainability often take a normative perspective in order to argue that impacts to local human and ecological welfare should take precedence in policymaking about immigration (Daly, 2006; Neumayer, 2006). Røpke (Røpke, 2006) takes a more balanced approach and argues that reasonably managed migration can be compatible with sustainable development. Heilmann (Heilmann, 2006)provides empirical evidence for such a conclusion and demonstrates that remittances can aid in sustainable development with proper governance. Similarly, Oldekop and colleagues (Oldekop et al., 2018) have documented examples in which re-forestation was fostered in Nepal as a result of out-migration.

\subsection{Incorporating Place and Time}

The discussion above emphasizes the point that the impacts of globalization are place specific. Geography, however, is not the only dimension in which scale needs to be considered. In addition to place representing a specific space, place can also connote a sense of connection to that specific space. Chapman (Chapman, 2006) states "places are those sites that evoke a profound sense of belonging - a feeling of placeness - where values (and virtues) are acquired; sense-of-place values include continuity (tradition), reciprocity (enduring cooperation), embodiment (belonging), integrity (obligation) and informed judgments (justice). On the contrary, space is an undifferentiated extension; it is defined mathematically through coordinates." Thus, a place-based understanding of sustainability must also include factors that shape the community's values about the space itself as well guide appropriate action. Only by incorporating geographic space with community view can we achieve sustainable communities for it is within places that communities exist and thrive.

When one takes a place-based perspective of sustainability rather than simply a spatial scale perspective, the history of the place becomes relevant, leading us to consider the context of sustainability in terms of temporal and spatial coordinates. Typically, when time is considered in sustainability discussions, it is the future that is considered, not the past. This tendency is largely driven by an emphasis on sustainable development as a plan. Within this view, time is rarely explicitly determined: while "long-term" is often used to describe the applicable time duration for sustainability, the duration is poorly defined.

Recognizing this deficiency, Costanza and Patten (Costanza \& Patten, 1995) argue that the longevity of the component parts of a system should determine the time target for sustainability. Holling and Gunderson (Holling \& Gunderson, 2002) also view the determination of temporal duration as being a necessary component of an answer to the question "what is to be sustained?" They state that the challenge is not to conserve things indefinitely, but "to conserve the ability to adapt to change, to be able to respond in a flexible way to uncertainty and surprises... A living system cannot be kept within some desirable state or on some desirable trajectory if adaptive capacity is continually lost" (Holling \& Gunderson, 2002). While more specificity in duration over which sustainability offers benefits, it is not fully sufficient. In focusing only on duration we miss important aspects of the factors that are historically necessary for the system to exist in the first place.

Thus, in order to understand how adaptation has enabled communities to be sustainable, one must look to the past, because it is only in retrospect that sustainability can be assessed with certainty (Costanza \& Patten, 1995). The study of climate change, for example, has begun to address this temporal dimension by using historical and archaeological evidence to examine the specific adaptations adopted by past populations to previous climate conditions (Adamson et al., 2018; Jackson et al., 2018). Historical approaches can uncover how traditional knowledge has led to place-specific adaptation practices, how historical factors create path-dependent responses, 
and how modern-day concepts, such as sustainability, were understood in the past (Adamson et al., 2018).

In this way, the use of a place-based consideration for community sustainability requires one to define a relative frame of reference against which practices can be evaluated. A place-based approach examines the historical context in which communities have existed. Such a frame of reference then provides us empirically-based information about how communities have adapted over time to respond to conditions in the context in which they have successfully persisted.

\subsection{Research Questions}

We seek to answer the following question: How do place and time factor into community's understanding of its own sustainability? In order to answer this question, we chose an iconic location with a unique history and current sustainability challenges, Rapa Nui (Easter Island), Chile. Our analysis is presented in two parts. First, we present an overview of the archaeological evidence for sustainability until European contact and historical evidence that shows how the society "collapsed." With that as context, we conducted interviews with six key governance leaders to explore what sustainability means to them in the present day. We anticipate that present-day concepts of sustainability are influenced by this community's unique past and the challenges of an island existing in an increasing globalized world.

\section{Archaeological and Historical Evidence of Sustainability}

\subsection{Collapse or Sustainability?}

Rapa Nui (Easter Island, Chile) is known worldwide for its megalithic statues called moai. Rapa Nui is only 161 $\mathrm{km}^{2}$ in area, is located thousands of kilometers from any other island or mainland South America, and lacks much in the way of natural resources (Figures 1 and 2). Rapa Nui presents an enigma for social scientists seeking to account for the roughly 1,000 multi-ton statues (moai), hundreds of which were transported kilometers across the volcanic terrain and placed atop massive stone-constructed platforms, or $a h u$. Most puzzling is the fact that in 1722, the first Europeans observed a population that numbered just a few thousand people. The stark contrast between the island's massive monuments, its limited resources, and the small population provided ample fodder for European speculation that the island once hosted a larger population under more prosperous conditions (Cook et al., 1777; La Pérouse et al., 1798). Such speculation has continued through contemporary times (Diamond, 1995).

Figure 1.

Figure 2.

The logic behind the reasoning for a large pre-contact population is not based on empirical evidence or direct observations but rather on the presumption that the number of statues and monuments were constructed during a time when resources were more plentiful and the population larger. Indeed, such speculations about resources, population, and the cause of the island's deforestation and cultural ruin began with one of the island's early European visitors. Based on a single day's visit in April 1786, French explorer Jean-François de Galaup La Pérouse speculated that the past Rapa Nui's inhabitants decimated the island's trees and that the present inhabitants were "indebted to the imprudence of their ancestors for their present unfortunate situation" (La Pérouse et al., 1798). This speculation forms much of the basis for the assumptions made by later authors. For example, many speculate about large population numbers (Puleston et al., 2017; Reuveny, 2012).

Beginning in the latter part of the 20th century with growing ecological awareness, authors conjectured the failure of a large prehistoric following environmental catastrophe. William Mulloy first published an account of precontact Rapa Nui society and speculated that the population invested in spectacular constructions, statues, and ceremonial activities leading to over-exploitation of the island's fragile resources and devastating warfare (Mulloy, 1974). Kirch (Kirch, 1984) echoed this story, writing that by the time of European contact the island had "already begun a downward spiral of cultural regression" and "crashed devastatingly."

Ponting (Ponting, 1992) widely spread the idea that the history of Rapa Nui was a case of unsustainability. In $A$ Green History of the World, Ponting asserts that "when the society was at its peak, it suddenly collapsed.... The cause of the collapse and the key to understanding the 'mysteries' of Easter Island was massive environmental degradation brought on by deforestation of the whole island" (Ponting, 1992) Deforestation, he argued, occurred due to the number of people required to move the gigantic statues coupled with the use of native trees that were 
used as rollers. He writes that "without trees, and so without canoes, the islanders were trapped in their remote home, unable to escape the consequences of their self-inflicted, environmental collapse" (Ponting, 1992). Ponting concludes his argument by stating that Rapa Nui, like the earth itself, "has only limited resources to support human society and all its demands" (Ponting, 1992).

Recent research, however, significantly challenges the conventional narrative of "collapse" for Rapa Nui. Over the past two decades of field research, archaeologists have greatly reshaped our knowledge of the island's pre-contact history (Hunt \& Lipo, 2018, 2011). Instead of an island that once had a large population and exceeded its own carrying capacity, the island was always resource-poor and populations found ways of successfully sustaining themselves over the 500 years that predate European arrival (Hunt \& Lipo, 2011; Peiser, 2005). Vast areas of the island were transformed into rock mulch gardens (Bork et al., 2004). These rock mulch gardens were innovative solutions made by prehistoric people to compensate for the natural constraints of the island's nutrient-poor soils (Ladefoged et al., 2013). Small walled gardens that are known as manavai also contributed to food production, likely used to grow plants such as taro, banana, and sugar cane that needed additional protection and care to flourish (Ayala-Bradford et al., 2005). Coastal fishing also contributed a significant portion to the diet, though at levels lower than other Polynesian islands (Jarman et al., 2017).

Though much of its current notoriety comes from assumptions of ecological catastrophe, current evidence supports a radically different account. Rather than a story of collapse, Rapa Nui is a case study of remarkable success and sustainability on a remote, resource-poor island that persisted until the arrival of Europeans in 1722.

\subsection{Rapa Nui History: The Actual Cause of "Collapse"}

Historical accounts provide ample documentation that the island radically changed with the arrival of Europeans, its engagement in a global economy, and the consequential impacts that included the introduction of disease, new economic resources, and slave raiding (Fischer, 2005; Hunt \& Lipo, 2011; Peiser, 2005). At some point after the arrival of Europeans in 1722 and potentially after the beginning of the 19th century, the culture of moai and ahu construction ultimately was abandoned (Robert J. DiNapoli, 2020; Simpson Jr. \& Dussubieux, 2018).

It is noteworthy that the evidence of disease, soil erosion, and environmental degradation often associated with "collapse" can be linked to the integration of the island into a global context. Cumulative impacts from foreign diseases such as smallpox, dysentery, and tuberculosis took a major toll on the islanders as they had little if any natural immunity. Whalers embedded in a global whale-oil economy began to raid the island for supplies and workers for their ships. Between 1862 and 1888, international slave-traders came from Peru seeking domestic servants. Islanders were recruited with promises, and sometimes just by force. Thousands of Rapanui died from disease or were taken during the raids. By 1877, the resident native population on the island had reached its alltime record low of just 111 adult individuals (Fischer, 2005).

Environmentally, the island was further transformed with the imposition of a large sheep ranch operated by the Williamson-Balfour company. Between 1888 and 1933, foreign ranch administrators brought as many as 60,000 sheep to the island (Charola, 1994). Sheep grazing resulted in massive gullies and sheet erosion across areas such as Poike on the eastern end of the island (Mieth \& Bork, 2005).

Overall, it is clear that the population of Rapa Nui suffered the impacts of globalization that this process strongly shaped the post-European contact history of the island. Indeed, the future of the island depends on resolving injustices that began in 1722 but have yet to be fully settled. Until the 1960s, the islanders were limited to the small town of Hanga Roa enclosed by a wall constructed to prevent native access to their island. Governed by Chile since 1888, Rapanui residents could not vote nor could they legally leave the island.

Over time, however, the Rapanui people have become increasingly engaged in self-governance. In 1965, Alfonso Rapu led a group of residents in an insurrection that forced the Chilean government to return parcels of land to the Rapanui. He was later elected mayor of the island. In 1966, this insurrection led to full Chilean citizenship for the islanders and in 1984, Sergio Rapu became the first appointed native governor and led the island through 1990. Since this time, the island has seen steady integration into the global economy through the rapid growth of tourism as well as increasing self-governance for the community. Most recently, Comunídad Indígena Polinésíca Ma'u Непиа -- the island's native heritage management, and conservation organization -- has taken over the management of the island's public natural and cultural resources (CODEIPA, 2015).

\section{Method}

\subsection{Data Collection}

In 2016, we undertook a research project to investigate the perspective of sustainability in the context of the island and its history by interviewing its governance leaders. Administratively, Rapa Nui is a province of the Valparaiso 
region of Chile, which has a population of over 1.7 million people located primarily on the mainland. As a province, it has an appointed governor who reports to the intendant of the region. A majority of the population of the island (87\%) lives within Hanga Roa, the only commune (municipality) on the island. Hanga Roa is the capital of the commune of Rapa Nui and has a mayor elected by its residents every four years. At the time of our research in 2016 (prior to the establishment of Comunídad Indígena Polínésíca Ma'u Henua), 43\% of the land area of Rapa Nui falls within the Rapa Nui National Park overseen by the National Forest Corporation (CONAF). CONAF is a private, non-profit corporation responsible for the management of the country's forest resources and overseen by the Ministry of Agriculture. Alongside the official governmental structure existed the Rapa Nui Parliament, an indigenous rights group established in 2001 by the Council of Elders (https://minorityrights.org/minorities/rapanui/). We selected the key informants based on their governance roles as a way of assessing the island's perspectives on sustainability from a place-based view. We conducted interviews with six key informants over five interview sessions. These key informants were:

- The governor of Rapa Nui in 2016.

- The first native governor of Rapa Nui, who served from 1984 to 1990 . He is currently a business owner and active in the tourism industry as well as a published archaeologist.

- The mayor of Hanga Roa in 2016, who had also served as governor of Rapa Nui from March to August 2010.

- Two members of the Rapa Nui Parliament.

- The 2016 Director of CONAF.

We conducted interviews with the 1984-1990 governor and mayor in English. Interviews with the director of CONAF and the 2016 governor took place in Spanish with the aid of a Rapanui translator. We conducted the interview with the two members of the Rapa Nui Parliament in Spanish, Rapanui, and English. One of the members of Parliament spoke English and the other spoke Rapanui. The English-speaking member of Parliament acted as translator for the Rapanui-speaking member. We audio-recorded all interviews, transcribed the Spanish and English portions, and then translated the Spanish portions into English. The interviews ranged from 45 to 60 minutes in length.

As part of our exploratory study, we structured the interviews around the question of what it means to be sustainable on Rapa Nui. Follow-up questions related to what each interviewee thought was needed for sustainability to be achieved. This tactic allowed us to explore topics such as education, tourism, the structure of government, and issues related to the environment. The interviewees largely controlled the direction of the interviews and the format offered an opportunity for different topics to emerge.

\subsection{Data Analysis}

Following Miles and colleagues (Miles et al., 2014), we analyzed the interview data using a variable-based approach that started with a provisional list of codes to which we added codes whenever the initial list proved insufficient. We used these codes to identify common themes between interviews, spatial and temporal aspects of sustainability, as well as to investigate the intersection between common themes and their spatial and temporal dimensions.

\section{Findings}

In our analyses, we found that three common themes emerged in the discussions about sustainability and challenges to achieving sustainability on Rapa Nui: higher education, tourism, and land use/administration. Each of these themes included aspects of space and time.

\subsection{Common Theme One: Higher Education}

Education was of great concern to the interviewees. As a small island with limited resources, there are no colleges or universities. Those individuals who seek higher education must travel to mainland Chile or attend another international university. While higher education was universally recognized as an important part of human development, the interviewees raised concerns about off-island higher education. One concern was focused on cost. While sending a son or daughter to mainland Chile for higher education was less expensive than a college or university in another country, the education still incurred substantial costs. Interestingly, despite the higher cost of international education, the interviewees expressed non-Chilean universities as preferable due to the fact that islanders view Chile as a colonizer. One interviewee noted, for example, that education offered on the Chilean mainland was a "colonization of their minds." Due to historical factors, mainland education was viewed as a threat to traditional knowledge, a knowledge that was viewed as essential to creating a sustainable way of life on Rapa 
Nui.

In this way, the cultural and environmental aspects of sustainability are inherently intertwined. Cultural knowledge -- gained through local traditions and place-based experiences -- is viewed as affecting all aspects of life, from governance to agricultural practices. While the interviewees all recognized that living in a global society requires new knowledge and that could only be obtained by higher education, local traditions remained central to the island's future. In this way, views about higher education were paradoxical—higher education was seen as critical to achieving sustainability, but also a threat to sustainability.

In this discussion of higher education, there are simultaneous spatial and temporal dimensions. The relevant geography for the higher education system for Rapanui individuals was, in effect, the entire world, with no local options for higher education. The closest opportunity for higher education is 3,510 kilometers away on mainland Chile. Temporally, the necessary education needed by a resident of Rapa Nui to succeed in contemporary times has changed from the past. Increasingly, individuals need not only traditional but also Western-based knowledge. Contemporary Western-based education, however, was not viewed as an acceptable replacement of traditional content and learning but rather supplemental. Education needs have changed over time as a reflection of the interaction of spatial and temporal scales - as Rapa Nui has become a global tourist destination, greater demands have been placed on the island. Tourism, however, is not the only driver for higher education. In fact, the tourism industry has made gainful employment possible for even those who lack a college education. Instead of essential, education is seen as enhancing human well-being through the improvements in medicine, engineering, and other non-traditional types of training. Even if tourism and in-migration to Rapa Nui were halted, it is doubtful that most residents would favor a return to a subsistence way of life-based solely on traditional knowledge.

\subsection{Common Theme Two: Tourism}

As can be seen in the discussion of higher education, the common themes are intertwined. Increases in the number of visitors due to global tourism has led to the island to require greater amounts of higher education necessary to bring financial, administrative, and scientific skills needed to deal with increased demands on the island's infrastructure and fragile ecosystem. The growth in the island's tourist industry, however, has simultaneously created productive employment opportunities for individuals who lack higher education. Similar to views on higher education, the interviewees viewed tourism as having positive and negative impacts. On the positive side, growth in tourism created unprecedented economic opportunities. On the negative side, the increase in the number of annual tourists was viewed as a threat to the culture and environment of Rapa Nui. The interviewees emphasized their desire for the island to attract what they referred to as "quality tourists;" i.e., visitors who would be willing to visit the island for a longer period of time in order to fully appreciate the living culture of the island. The interviewees reasoned that these visitors would bring greater benefits and fewer negative impacts than those who might be arriving just to check "seeing the moai" off of their bucket list.

The spatial and temporal dimensions of tourism on the island are similar to those for higher education. The relevant "system" in which Rapa Nui tourism takes place is the globe-people come from all over the Earth to Rapa Nui. As in the case of higher education, the temporal dimension of tourism includes a strong conflict between modern and traditional ways. While tourists travel to Rapa Nui to see cultural artifacts of the past, by doing so they also impact the ability of the living culture to sustain itself. This conflict is played out in the next theme-land use/administration.

\subsection{Common Theme Three: Land Use/Administration}

A third theme that emerged from the interview was a common concern about the use and administration of land area on Rapa Nui. In 2016, a major source of conflict across the island was CONAF's long-standing administration of the Rapa Nui National Park. Intended to protect its cultural artifacts and fragile ecosystem, the Park comprises $43 \%$ of the island, much of which is no longer available for private interests or its traditional uses. This system of protection has important spatial and temporal dimensions. The obvious spatial dimension is the amount of land area encompassed by the Park. The spatial dimension, however, is conceivably broader than just the island's 166 sq. km land area. Ostensibly, wise management of the Park includes working to protect the island ecosystem terrestrial, marine, atmospheric -- as well as the cultural traditions and materials of the Rapanui people from the tourists who come to see it. Yet, effectively accomplishing this task has the potential to limit opportunities for economic and social change. One fear is that over-zealous management of the past is driven to preserve the island museum-like "historic" state for tourists. And since tourists are international as well as Chilean, it is this global spatial dimension that results in impacts to land use.

Preservation has an obvious temporal dimension as well. Cultural preservation, however, can take many forms. If the goal is to preserve artifacts in their current state, or to restore them to a previous state, the island becomes a 
museum. Cultural traditions and practices that are dynamic, changing, and vital parts of life, however, would suffer. For example, if the island is to sustain its resident population, reduce its global impact, and increase resiliency by producing more local food, at least some of the pre-contact agriculture features that are widely found across the island and that once provided resources must be replaced by more intensive agricultural practices in the limited space outside of the Park. These practices, however, have substantial costs: with limited local resources critical material such as compost must be transported $3,700 \mathrm{~km}$. For the cultural landscape to be maximally preserved, food and other essential resources must be transported long distances. Such a strategy though decreases resiliency and has substantial global costs in terms of energy consumption and carbon production. Clearly, a balance needs to be struck to meet the needs of maintaining the cultural traditions that have continued to support the island's way of life while also adapting to growing contemporary demands.

\section{Discussion: Bringing the Past and present Together}

Although the environment, economy, equity, governance, and culture are often discussed as sustainability pillars, the evidence presented in this article suggests that these factors are better described as dimensions of sustainability that are part of the place that forms the basis of sustainable communities. Pillars are separate and distinguishable from what they uphold. Culture, governance, economy, environment, and equity, however, are inherently intertwined into aspects of the history of Rapa Nui from pre-European contact to the present day. All of these factors are necessary for a community to be sustainable.

\subsection{Sustainability and Time}

How do Rapa Nui practices and policies fare over time when they are evaluated on the basis of the definition of a sustainable community offered by Mischen and colleagues (Mischen et al., 2019)? In terms of self-determination governance processes, the archaeological evidence suggests that the pre-contact islanders lacked a strong islandwide hierarchical governance structure (Hunt \& Lipo, 2011). Islanders were, however, able to equitably share the resources of the island. The central need to share due to the inherent unpredictable yet non-defensible resources resulted in "equitable provisioning" of the resources that were available at that time (R.J. DiNapoli et al., 2017). That the Rapanui were able to sustain this pattern of consumption for around 500 years points to the fact that this strategy did not negatively impact future generations. Instead, the island was, at least for the duration of its preEuropean history and was inhabited by sustainable communities. Health, education, and material well-being, relative to our contemporary standards, however, were not possible given the temporal context in which the population lived.

Upon contact with Europeans, Rapa Nui clearly became unsustainable from the perspective of the Rapanui people. Governance changed from cooperative co-existence and was replaced by an activity that emphasized the acquisition of private goods - the Tangata Manu competition - and which conveyed privileges to the winning clan. By the late 1880s, native Rapanui became confined to a small part of the island and excluded from governance as Chile annexed Rapa Nui. It was not until 1966 that the Rapanui people were granted full citizenship of Chile. The health of native Rapanui people was severely impacted as Europeans brought diseases to which they had no natural immunity. Combined with slave raiding, this reduced the population to just several hundred individuals living on the island by the early part of the $20^{\text {th }}$ century. The environment of the island was also radically changed by the sheep ranch, which resulted in a degraded landscape, erosion, and reduced future fertility of the island.

In the present-day, as indigenous rights are being restored, governance, health, education, and material well-being have improved on the island. While higher education must be obtained off the island, elementary and secondary education is provided and includes instruction in the native language as well as Spanish. There are many concerns, however, regarding the future of Rapa Nui as tourism increases resource use beyond a sustainable level. Furthermore, higher education, while viewed as necessary, also constitutes a threat to the preservation of the culture, and with that, the knowledge of how to live on a resource-constrained island. Lastly, the tension between tourism and land-use reduces the self-sufficiency of the island and introduces the question of what is being preserved (artifacts or living culture) and for whom.

Taken together, we see how viewing sustainability over time reveals that it is not a specific state to be achieved, but an ever-changing set of values that informs governance and resource-use decisions. As Holling and Gunderson (Holling \& Gunderson, 2002) point out, sustainability is about maintaining adaptive capacity. One could argue that prehistoric Rapanui culture and practices, while perfectly adapted to their island environment, lacked the adaptive capacity to deal with European invaders. Such a conclusion, however, is in contrast to their remarkable success in sustaining cultural traditions and language, despite colonization. Despite horrific historical events brought by colonizers, the islanders have fought for indigenous rights that have led to the more favorable position that they currently hold. In the present, there remains a strong desire to retain and reinforce the knowledge of the past as 
this knowledge has substantial potential to help islanders adapt to future changes. There is, however, a concomitant recognition that additional education will be necessary for them to continue to adapt to shifting environmental, economic, and social factors. Likewise, the interrelated issues of land-use and tourism can be couched in terms of adaptive capacity as well. Will the income from tourism allow the Rapanui to live more sustainably on the island or will tourism have long-term negative consequences? How much land should be conserved in a museum-like state and how much should be used to provide a landscape for traditional activities? How much land must be utilized to increase local sustainability and resilience of food resources. Ultimately, Rapanui people must answer the question: what is to be sustained?

\subsection{Sustainability and Place}

An important part of the definition of a sustainable community offered by Mischen and colleagues (2019) is that it should not negatively impact other communities. When viewed over time, Rapa Nui has endured significant impacts due to the actions of external groups. Presently, however, the island is a net importer of goods and labor and thus has a significant impact on communities that live off-island. The force driving these impacts is globalization. Human settlement of Rapa Nui, 18th century European contact, and the first commercial airline flights are all extrinsic and disruptive events that brought different groups of people to the island, and consequently changed what it means for the island to be sustainable. Viewed over a long time-frame, globalization is not a new phenomenon, but one that began with the movement of Homo sapiens out of Africa. The events that have transpired on Rapa Nui, in this sense, are only the last in a series caused by human expansion across the globe. Population growth and technological change have accelerated this process and the consequences of globalization. Viewed in this way, globalization is not just about the global movement of goods or services, but is part-and-parcel with human migration. Initially, human migration patterns stemmed from human populations seeking new and uninhabited territory. At the point in which the earth's habitable lands became occupied, human migration turned to those locations with more resources leading some groups to conquer others through technology, disease, or economic interventions. Now, human migration results from individuals seeking better lives or opportunities to acquire economic resources and experiences. We see this effect of globalization on inhabitation, then colonization, and now tourism and migration for economic opportunity.

Tourism and education reflect the tension between the benefits and drawbacks of globalization. Without tourism, it is likely that life on Rapa Nui would not be that different today from pre-colonial times as islander life would primarily depend on the same local resources available in pre-contact times. Since the island is too small and remote for other forms of economic development to enhance human well-being, there are physical constraints on the array of opportunities for sustainable living. On the other hand, unregulated tourism is likely to destroy the culture that draws tourists to the island in the first place, as well as undermine a sense of community for native Rapanui. Likewise, higher education is a necessity and a threat since it currently must be obtained off the island. These facts speak to the importance of taking the socioeconomic benefits of material and resource flows into consideration (Huang et al., 2015). While tourism increases the flow of resources that must occur through the ecological, social, and economic "systems" of Rapa Nui, it makes a number of health and education benefits possible. Tourism can lead to scenarios in which the island exceeds its carrying capacity. Thus, flows of materials from off-island remain necessary to keep the island from devastating the island. However, the increased importation of goods, labor, food, and energy has greatly expanded the island's ecological footprint as current live now depends significantly upon the resources of other places, with the potential of negative impacts on them.

\subsection{Conclusions}

By taking a place-based approach to the study of sustainable communities and combining archaeological evidence with interviews with key governance leaders, we have been able to explore the culture, governance, economic, environmental, and equity dimensions of sustainability over space and time. Studying the island community of Rapa Nui (Easter Island), Chile, enhances our ability to focus on the linkages between the local and the global. We have explored the temporal dimension by comparing the past and present, and also by discovering the links between the past and present engendered by the preservation of indigenous culture.

Recent archaeological evidence indicates that the prehistoric culture of the Rapanui people did not result in "ecocide" as commonly argued, but allowed island inhabitants to transform their environment in ways that allowed them to reliably sustain themselves for hundreds of years before European contact. Since the disruption that European contact brought, the Rapanui people have been fighting to maintain their culture, through a period of colonization, to the present day, in which indigenous rights and governance are being restored. Present-day Rapa Nui, however, faces sustainability challenges quite unlike those in pre-colonial times, as expectations for the standard of living have increased and globalization has made the island accessible to the world despite its extremely 
remote location.

Based on these considerations, we contend that our exploration yields three important insights for our understanding of sustainability. First, culture, governance, economy, environment, and equity, often described as "pillars" of sustainability, are inseparable and therefore better described as dimensions of sustainability. These factors are part of the place in which sustainable communities exist and must be integrated into analyses. Second, our findings demonstrate that we must adopt standards for sustainable communities that can change through time. Third, globalization can be viewed as a driving force behind these changing views of sustainability. Globalization, however, should not be thought of as simply a threat to sustainability, but as an interaction that takes place in positive and negative ways to affect human and environmental considerations. The considerations, of course, must be balanced for sustainability to be achieved at local and global levels.

Although we selected Rapa Nui to highlight the interactions among the dimensions of sustainable communities as well as the role of place in examining sustainability, this study provides important lessons for less famous communities. Every community will have its own sense of itself and its history. Communities will differ based on what government entities can and cannot do. Sustainability issues necessarily vary by place. To the extent that government structures are involved in creating sustainability solutions, developing a strong understanding of the place in which communities exist is critical for long-term success.

\section{References}

Adamson, G. C. D., Hannaford, M. J., \& Rohland, E. J. (2018). Re-thinking the present: The role of a historical focus in climate change adaptation research. Global Environmental Change, 48, 195-205. https://doi.org/10.1016/j.gloenvcha.2017.12.003

Allen, R. (1980). How to Save the World: Strategy for World Conservation. Kogan Page Ltd.

Ayala-Bradford, I., Lipo, C. P., \& Hunt, T. L. (2005). The use of satellite imagery to study prehistoric agricultural features (manavai) on Rapa Nui. In A. Seelendfreund (Ed.), The use of satellite imagery to study prehistoric agricultural features (manavai) on Rapa Nui.: Vol. Renaca Papers: VI International Conference on Rapa Nui and the Pacific (pp. 113-123). Easter Island Foundation and University of Valparaiso.

Baek, J., Cho, Y., \& Koo, W. W. (2009). The environmental consequences of globalization: A country-specific time-series analysis. Ecological Economics, 68(8-9), 2255-2264. https://doi.org/10.1016/j.ecolecon.2009.02.021

Bork, H.-R., Mieth, A., \& Tschochner, B. (2004). Nothing but stones? A review of the extent and technical efforts of prehistoric stone mulching on Rapa Nui. Rapa Nui Journal, 18, 10-14.

Brown, L. R. (1981). Building a Sustainable Society: W.W. Norton \& Company, Inc.

Brown, L. R. (1984). State of the World: A Worldwatch Insititute Report Toward a Sustainable Society. Worldwatch Institute.

Chapman, R. L. (2006). Confessions of a Malthusian restrictionist. Ecological Economics, 59(2), 214-219. https://doi.org/10.1016/j.ecolecon.2005.12.020

Charola, A. E. (1994). Easter Island. The Heritage and its Conservation. World Monuments Fund.

CODEIPA. (2015). Ma'u Henua: Propuesta De Nueva Administracion Parque Nacional Rapa Nui. Retrieved from $\mathrm{http} / / / \mathrm{ciperchile.cl/wp-content/uploads/PROPUESTA-MAU-HENUA.pdf}$

Cole, M. A., Elliott, R. J. R., \& Shimamoto, K. (2006). Globalization, firm-level characteristics and environmental management: A study of Japan. Ecological Economics, 59(3), 312-323. https://doi.org/10.1016/j.ecolecon.2005.10.019

Cook, J., Furneaux, T., Hodges, W., \& Pringle, J. (1777). A voyage towards the South Pole, and round the world. Performed in His Majesty's ships the Resolution and Adventure, in the years 1772, 1773, 1774, and 1775 (3725170; Vol. 1-2). W. Strahan and T. Cadell.

Costanza, R., \& Patten, B. C. (1995). Defining and predicting sustainability. Ecological Economics, 15(3), $193-$ 196. https://doi.org/10.1016/0921-8009(95)00048-8

Daly, H. E. (2006). Population, migration, and globalization. Ecological Economics, 4.

Diamond, J. (1995). Easter's end. Discover, 9, 62-69.

Diamond, J. (2005). Collapse: How Societies Choose to Fail or Succeed. Viking Press.

DiNapoli, R. J. (2020). Factors Influencing the Construction of Monumental Architecture: A Rapa Nui (Easter 
Island) Case Study [PhD Dissertation, University of Oregon]. Retrieved from https://scholarsbank.uoregon.edu/xmlui/handle/1794/25707

DiNapoli, R.J., Morrison, A. E., Lipo, C. P., Hunt, T. L., \& Lane, B. G. (2017). East Polynesian islands as models of cultural divergence: The case of Rapa Nui and Rapa Iti. Journal of Island and Coastal Archaeology, 13(2), $206-223$

Elsler, L. G., Drohan, S. E., Schlüter, M., Watson, J. R., \& Levin, S. A. (2019). Local, Global, Multi-Level: Market Structure and Multi-Species Fishery Dynamics. Ecological Economics, 156, $185-195$. https://doi.org/10.1016/j.ecolecon.2018.09.008

Fischer, S. R. (2005). Island at the End of the World: The turbulent history of Easter Island. University of Chicago Press.

Grau, H. R., \& Aide, M. (2008). Globalization and Land-Use Transitions in Latin America. Ecology and Society, 13(2). https://doi.org/10.5751/ES-02559-130216

Heilmann, C. (2006). Remittances and the migration-development nexus-Challenges for the sustainable governance of migration. Ecological Economics, 59(2), 231-236. https://doi.org/10.1016/j.ecolecon.2005.11.037

Holling, C. S., \& Gunderson, L. H. (2002). Panarchy: Understanding transformations in human and natural systems. Island Press.

Huang, L., Wu, J., \& Yan, L. (2015). Defining and measuring urban sustainability: A review of indicators. Landscape Ecology, 30(7), 1175-1193. https://doi.org/10.1007/s10980-015-0208-2

Hunt, T. L., \& Lipo, C. (2018). The Archaeology of Rapa Nui (Easter Island). In E. E. Cochrane, \& T. L. Hunt (Eds.), The Oxford Handbook of Prehistoric Oceania (pp. 416-449). Oxford University Press. Retrieved from http://www.oxfordhandbooks.com/view/10.1093/oxfordhb/9780199925070.001.0001/oxfordhb9780199925070-e-026

Hunt, T. L., \& Lipo, C. P. (2011). Easter Island's Complex History. Nature, 479(7371), 41-41.

Jackson, R. C., Dugmore, A. J., \& Riede, F. (2018). Rediscovering lessons of adaptation from the past. Global Environmental Change, 52, 58-65. https://doi.org/10.1016/j.gloenvcha.2018.05.006

Jarman, C. L., Larsen, T., Hunt, T., Lipo, C., Solsvik, R., Wallsgrove, N., Ka’apu-Lyons, C., Close, H. G., \& Popp, B. N. (2017). Diet of the prehistoric population of Rapa Nui (Easter Island, Chile) shows environmental adaptation and resilience. American Journal of Physical Anthropology, 164(2), 343-361.

Kirch, P. V. (1984). The Evolution of Polynesian Chiefdoms. Cambridge University Press.

La Pérouse, J.-F., Moreau, J.-M., de Vancy, D., Ozanne, N.-M., \& Martinière, L. (1798). Voyage de La Pérouse autour du monde (Vol. 3). Chez Plassan.

Ladefoged, T. N., Flaws, A., \& Stevenson, C. M. (2013). The Distribution of Rock Gardens on Rapa Nui (Easter Island) as Determined from Satellite Imagery. Journal of Archaeological Science, 40, 1203-1212.

Lima, M. G. B., Persson, U. M., \& Meyfroidt, P. (2019). Leakage and boosting effects in environmental governance: A framework for analysis. Environmental Research Letters, 14(10), 105006. https://doi.org/10.1088/17489326/ab4551

Marcotullio, P. J. (2001). Asian urban sustainability in the era of globalization. Habitat International, 25(4), 577598. https://doi.org/10.1016/S0197-3975(01)00025-X

Mieth, A., \& Bork, H. R. (2005). History, origin and extent of soil erosion on Easter Island (Rapa Nui). Catena, 63(2-3), 244-260.

Miles, M. B., Huberman, A. M., \& Saldana, J. (2014). Qualitative data analysis: A methods sourcebook (3rd ed.). Sage.

Mischen, P., Homsy, G., Lipo, C., Holahan, R., Imbruce, V., Pape, A., Zhu, W., Graney, J., Zhang, Z., Holmes, L., \& Reina, M. (2019). A Foundation for Measuring Community Sustainability. Sustainability, 11(7), 1903. https://doi.org/10.3390/su11071903

Mulloy, W. (1974). Contemplate the navel of the world. Rapa Nui Journal, 26, 25-33.

Neumayer, E. (2006). The environment: One more reason to keep immigrants out? Ecological Economics, 59(2), 204-207. https://doi.org/10.1016/j.ecolecon.2005.11.035 
Oldekop, J. A., Sims, K. R. E., Whittingham, M. J., \& Agrawal, A. (2018). An upside to globalization: International outmigration drives reforestation in Nepal. Global Environmental Change, 52, 66-74. https://doi.org/10.1016/j.gloenvcha.2018.06.004

Peiser, B. (2005). From Genocide to Ecocide: The Rape of Rapa Nui. Energy \& Environment, 16, 513-539.

Ponting, C. (1992). A Green History of the World. Penguin.

Puleston, C. O., Ladefoged, T. N., Haoa, S., Chadwick, O. A., Vitousek, P. M., \& Stevenson, C. M. (2017). Rain, sun, soil and sweat: A consideration of population limits on Rapa Nui (Easter Island) before European contact. Frontiers in Ecology and Evolution, 5, 69.

Reuveny, R. (2012). Taking Stock of Malthus: Modeling the Collapse of Historical Civilizations. Annual Review of Resource Economics, 4(1), 303-329. https://doi.org/10.1146/annurev-resource-110811-114537

Røpke, I. (2006). Migration and sustainability-Compatible or contradictory? Ecological Economics, 59(2), 191194. https://doi.org/10.1016/j.ecolecon.2005.11.033

Rueda, X., \& Lambin, E. F. (2013). Responding to Globalization: Impacts of Certification on Colombian SmallScale Coffee Growers. Ecology and Society, 18(3). https://doi.org/10.5751/ES-05595-180321

Simpson Jr., D. F., \& Dussubieux, L. (2018). A collapsed narrative? Geochemistry and spatial distribution of basalt quarries and fine-grained artifacts reveal communal use of stone on Rapa Nui (Easter Island). Journal of Archaeological Science: Reports, 18, 370-385. https://doi.org/10.1016/j.jasrep.2018.01.038

World Commission on Environment and Development. (1987). Our Common Future. Oxford University Press.

\section{Copyrights}

Copyright for this article is retained by the author(s), with first publication rights granted to the journal.

This is an open-access article distributed under the terms and conditions of the Creative Commons Attribution license (http://creativecommons.org/licenses/by/4.0/). 